\title{
The low-latitude boundary layer: Application of ISTP advances to past data
}

Conference or Workshop Item

Published Version

Lockwood, M. and Hapgood, M. A. (1999) The low-latitude boundary layer: Application of ISTP advances to past data. In: Toward Solar Max 2000: The Present Achievements and Future Opportunities of ISTP and GEM, February 10-13, 1998, Yosemite Park, California, USA, pp. 103-111. doi: https://doi.org/10.1029/GM109p0103 (in "The Physics of SunEarth Plasma and Field Processes" ed. J. Burch, AGU Monograph 109, 103-111, doi: 10.1029/GM109p0103, 1999) Available at https://centaur.reading.ac.uk/38750/

It is advisable to refer to the publisher's version if you intend to cite from the work. See Guidance on citing.

Published version at: http://onlinelibrary.wiley.com/doi/10.1029/GM109p0103/summary

To link to this article DOI: http://dx.doi.org/10.1029/GM109p0103

Publisher statement: in "The Physics of Sun-Earth Plasma and Field Processes" Proc 1998 Yosemite Workshop "Toward Solar Max 2000: The Present Achievements and Future Opportunities of ISTP and GEM". ed. J. Burch, AGU Monograph 109, 1999

All outputs in CentAUR are protected by Intellectual Property Rights law, including copyright law. Copyright and IPR is retained by the creators or other copyright holders. Terms and conditions for use of this material are defined in the End User Agreement. 


\section{www.reading.ac.uk/centaur}

\section{CentAUR}

Central Archive at the University of Reading

Reading's research outputs online 


\title{
The Low-Latitude Boundary Layer: Application of ISTP Advances to Past Data
}

\author{
M. Lockwood and M. A. Hapgood \\ Rutherford Appleton Laboratory, Chilton, UK
}

The destruction of the four Cluster craft was a major loss to the planned ISTP effort, of which studies of the magnetopause and low-latitude boundary layer (LLBL) were an important part. While awaiting the re-flight mission, Cluster-II, we have been applying advances in our understanding made using other ISTP craft (like Polar and Wind) and using ground-based facilities (in particular the EISCAT incoherent scatter radars and the SuperDARN HF coherent radars) to measurements of the LLBL made in 1984 and 1985 by the AMPTE-UKS and -IRM spacecraft pair. In particular, one unexplained result of the AMPTE mission was that the electron characteristics could, in nearly all cases, order independent measurements near the magnetopause, such as the magnetic field, ion temperatures and the plasma flow. Studies of the cusp have shown that the precipitation is ordered by the time-elapsed since the field line was opened by reconnection. This insight has allowed us to reanalyse the AMPTE data and show that the ordering by the transition parameter is also due to the variation of time elapsed since reconnection, with the important implication that reconnection usually coats most of the dayside magnetopause with at least some newly-opened field lines. In addition, we can use the electron characteristics to isolate features like RDs, slow-mode shocks and slow-mode expansion fans. The ion characteristics can be used to compute the reconnection rate. We here retrospectively apply these new techniques, developed in the ISTP era, to a much-studied flux transfer event observed by the AMPTE satellites. As a result, we gain new understanding of its cause and structure.

\section{THE MAGNETOPAUSE TRANSITION PARAMETER}

The magnetopause transition parameter was based on the work of Hall et al. [1985] and Bryant and Riggs [1989] and exploits the observed anti-correlation of electron density and temperature, also noted by Sckopke et al. [1981] and Phan et al. [1997]. Hapgood and Bryant [1992] developed its definition and implementation. The electron density, $N_{\mathrm{e}}$, is plotted as a function of an electron temperature, $T_{e}$ on a $\log -\log$ scale and the characteristic

Sun-Earth Plasma Connections

Geophysical Monograph 109

Copyright 1999 by the American Geophysical Union variation fitted with a polynomial. (In fact, slightly better results are usually obtained by using the perpendicular electron temperature, $\left.T_{\mathrm{e} \perp}\right)$. The transition parameter $\tau$ is the percentage distance along that fitted curve, a value of 0 being ascribed to the magnetosheath end of the curve and 100 being at the magnetospheric end.

The anti-correlation of $N_{\mathrm{e}}$ and $T_{\mathrm{e}}$ over much (but not all) of the curve can be explained as the change in the moments with a changing ratio of the magnetosheath to the magnetospheric components of an electron gas. Thus, for example, an increased sheath component of the electron gas will decrease the temperature of the total distribution, whilst increasing the density. Almost any process which causes a mixing of the two electron populations (of which reconnection is just one example) could cause this. Thus the existence of a transition parameter is not surprising. What is 
extraordinary is how well it orders independently-measures parameters like the magnetic field, the ion spectrum (and its moments) and the plasma flow [Hapgood and Bryant, 1992]. Data sequences in these parameters showing complex variations with observation time, $t_{s}$ (such as, for example, would be obtained for a series of multiple full and/or partial boundary crossings) give simple variations, with very little scatter, when plotted as a function of transition parameter, $\tau$. This ordering by the transition parameter was found to be effective in 41 out of 44 magnetopause crossings by AMPTE-UKS and neither surface waves nor flux transfer events (FTEs) disrupt it [Bryant and Riggs, 1988; Hapgood and Lockwood, 1995]. The success of the transition parameter, based only on the characteristics of the electron gas, in ordering the AMPTE data on the magnetic field and ion gas implied an underlying physical ordering of the particles and fields of the magnetopause boundary layer. However, the nature of that ordering and why it was present was not understood.

\section{MODELLING THE INJECTED MAGNETOSHEATH ION POPULATION}

Models of ion behaviour in the magnetosphere have recently been developed and successfully used to predict signatures of ion precipitation into the cusp ionosphere [Onsager et al., 1993; Onsager, 1994; Lockwood and Smith, 1994; Lockwood, 1995; Lockwood and Davis, 1996b; Lockwood et al., 1997]. These models allow for four main elements: (1) the spatial variations of the magnetosheath density and temperature (to date, gas dynamic predictions have been employed [Sprieter et al., 1966]); (2) the evolution of reconnected field lines over the magnetopause, as predicted by Cowley and Owen [1989]; (3) the theory of the ion acceleration and distribution functions at the magnetopause current sheet [Cowley, 1982] and (4) the time-of-flight velocity filter effect of ion motion along convecting field lines [Rosenbauer et al., 1975; Reiff et al., 1977]. These models of magnetosheath ion injection and transport have been very successful in reproducing the distribution functions of the precipitating cusp ions at low and middle altitudes both during steady-state conditions [Onsager et al., 1993 and Lockwood, 1997, respectively] and for periods when magnetopause reconnection is pulsed [Lockwood and Davis, 1996b; and Lockwood et al., 1998, respectively].

A refinement of the model of Cowley [1982] has been introduced by Lockwood et al. [1996], who allowed for reflection of magnetospheric ions off the Alfvén wave (hereafter called a rotational discontinuity, RD) on the interior edge of the open LLBL, as well as at the main RD (i.e., the magnetopause itself) on the outer edge of the LLBL. The magnetopause is an RD emanating from the reconnection site and standing in the inflow into the magnetopause from the magnetosheath. Correspondingly, the interior RD stands in the inflow from the magnetospheric side of the boundary. The theory of Cowley allows for the reflection of ions that are incident on an RD by flowing along the reconnected field lines, as well as their transmission through the RD. Cowley assumed that $50 \%$ of the incident ions were reflected, and 50\% transmitted, a ratio which was found to be roughly correct in the case studied by Fuselier et al. [1991]. Recently, we have been able to self- consistently evaluate these reflection coefficients by using kinetic theory of Cowley [1982], taking the moments of the predicted distribution functions and then iterating the reflection coefficients until the moments obey the fluid conservation equations for an $\mathrm{RD}$ (conservation of mass, normal momentum, tangential momentum and energy), as given by Hudson [1970]. With the addition of the interior RD, Lockwood et al. [1996] were able to model energetic ion precipitation at the equatorward edge of the cusp dispersion ramp, reproducing the observed spectra as well as the moments of the ion distribution. The model, with this extension, was also successfully employed by Lockwood [1997] and Lockwood and Moen [1996] to match observed ion precipitation distribution functions and fluxes, respectively.

The time-dependent version of the model computes the ion spectrum seen at a given location relative to the reconnection $\mathrm{X}$-line, as a function to the time elapsed since reconnection, $\left(t_{s}-t_{o}\right)$, where $t_{s}$ is the time that a field line is observed and $t_{o}$ is the time that it was reconnected. The importance of considering the precipitation as a function of $\left(t_{s}-t_{0}\right)$ was revealed by studies of poleward-moving transients in the cusp, as seen by optical imagers [Sandholt et al., 1990], the EISCAT incoherent scatter radars [Lockwood et al., 1993] and the Halley Bay and CUTLASS HF radars [Pinnock et al., 1995]; Neudegg et al. [1998], as explained by Lockwood and Davis [1996b]. This concept has been tested using ISTP satellite data. Lockwood et al. [1998] applied the model to fit the energy-time spectrograms of injected cusp ions seen by the Hydra instrument on the Polar satellite at middle altitudes.. Specifically, they fitted the sawtooth form for ions which have been injected, mirrored below the satellite and were observed moving upward. This completely prescribed the predictions for downgoing, zero pitch-angle injected ions which reach the satellite directly. Thus comparison with the observed downgoing ions was a blind test which verified the model and that reconnection was taking place mainly in short pulses.

\section{HOW THE TRANSITION PARAMETER WORKS}

The ion model discussed above has been used by Lockwood and Hapgood [1997] to give an important insight into how the magnetopause transition parameter ordering 
works. This was achieved by returning to the AMPTE data, using the understanding and the model of the ion gas derived and tested using ISTP data. In particular, Lockwood and Hapgood [1998] have revisited a much-studied flux transfer event (FTE), observed by the AMPTE-UKS and IRM satellites around 10:46 UT on 28 October 1984 during an outbound magnetopause crossing. The satellites were at a GSM latitude of $25.7^{\circ}$ (northern hemisphere) and at a magnetic local time of 08:55 (i.e. in the mid-morning sector). They were separated by $180 \mathrm{~km}$ in a direction roughly aligned with the boundary-normal (as determined from the magnetopause crossing by UKS which took place considerably later, at 11:45-12:45 UT), with UKS closer to the boundary than IRM. This event was first reported by Rijnbeek et al. [1987] who noted its layered structure. Subsequently, it has been the subject of studies by Farrugia et al. [1988], Lockwood et al., [1988], Bryant and Riggs [1989], Sibeck [1992], Sibeck and Smith [1992], and Smith and Owen, [1992]. Rijnbeek et al. [1987] and Farrugia et al. [1988] showed that there was a high-pressure core at the event centre predominantly due to particle pressure, but that outside this was a layer of high magnetic pressure and low particle pressure. The origin of this high pressure core of some FTEs has never been satisfactorily explained [Paschmann et al., 1982].

The cusp ion model can be applied to the open lowlatitude boundary layer at the magnetopause data, the only difference being that the satellite is relatively close to the reconnection site, compared to spacecraft at middle of low altitudes. Figure 1 illustrates the general principles by showing schematically an open LLBL (reconnection outflow layer) produced by (in this case steady) reconnection at $X$. The figure shows the separatrices $s$ (which pass through $X$ and for which the time elapsed since reconnection $\left(t_{s}-t_{o}\right)$ is zero) and four other newly-opened field lines as they evolve away from $X$ with increasing reconnection $\left(t_{s}-t_{0}\right)$. Standing in the inflow to the magnetopause are the exterior and interior RDs (the dashed lines $\mathrm{m}$ and $\mathrm{i}$ ). At a given distance from the $\mathrm{X}$-line to the satellite, $d$, the $\left(t_{s}-t_{o}\right)$ increases inside the LLBL as the satellite (UKS) approaches the exterior RD (i.e. the magnetopause): $\left(t_{s}-t_{o}\right)$ is zero at the interior separatrix and reaches a maximum value (for that $d$ ) at the magnetopause. Outside the magnetopause, in the magnetosheath boundary layer (MSBL), $\left(t_{s}-t_{0}\right)$ decreases again, reaching zero at the exterior separatrix. Outside the separatrices $\left(t_{s}-t_{o}\right)$ is negative (i.e. the field lines have yet to be reconnected) but $\left(t_{s}-t_{o}\right)$ has influence on neither the plasma nor the field. Ions reaching the satellite have a spread of field-aligned velocities and follow trajectories within the dark grey shaded wedge (the lowest energy ions having the longest flight time and having originated at the reconnection site, the highest energy ions (with fluxes that are detectable) crossing the magnetopause considerably closer to the

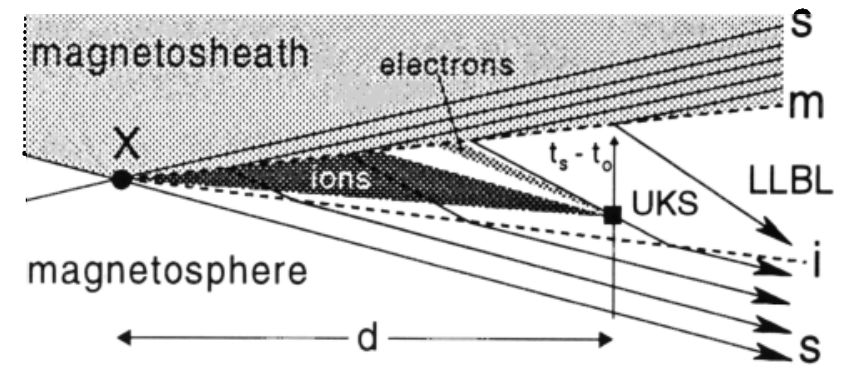

Figure 1. Schematic of AMPTE-UKS in the open LBL, between the magnetopause ( $\mathrm{m}$, also referred to as the exterior $\mathrm{RD}$, e) and interior (i) Alfvén waves emanating from the reconnection site (Xline), $\mathbf{X}$. Field lines evolving away from $\mathbf{X}$ are shown at five elapsed times since they were opened $\left(t_{\mathrm{s}}-t_{\mathrm{o}}\right)$, including zero for the magnetic separatrices (s). The spectrum of sheath ions reaching UKS has a spread of trajectories shown by the dark shaded wedge, the trajectories of the sheath electrons are much closer to field-aligned (lighter shaded wedge). The populations seen depend on UKS's depth into the LLBL, i.e. on the $\left(t_{\mathrm{s}}-t_{\mathrm{o}}\right)$ at a given distance $d$ from $X$.

satellite. The electrons reaching the satellite have a much higher field-aligned velocities and have trajectories which are closer to field-aligned and are within the lighter grey wedge. Because quasi-neutrality is maintained, the number of sheath electrons reaching the satellite is approximately the same as the number of sheath ions, the latter being a function of the distance $d$ and the time elapsed since reconnection $\left(t_{s}-t_{o}\right)$, i.e. it depends on how deep into the LLBL the satellite is situated.

Figure 2 shows the results of least-squares fitting the observed moments of the ion gas during this FTE, using the ion model discussed above. The distance between the satellite and the $\mathrm{X}$ line, $d$, is assumed to be $8 \mathrm{R}_{\mathrm{B}}$ (see later). The plot shows the moments of the ion gas as a function of observation time $t_{s}$ (given on the figure axis in seconds after 10:43UT). The histograms are the observed values and the lines are the fitted model values. The procedure adopted was to vary the value of the time elapsed since reconnection $\left(t_{s}-t_{o}\right)$ at every observation time $t_{s}$, until the best fits to the ion number density $N$ and temperature $T$ were obtained. This prescribes the variation in the ion pressure, $P$, but the number density at energies above $1 \mathrm{keV}, N_{[\mathrm{E}>1 \mathrm{keV}}$, and field-parallel velocity $V_{\text {para }}$ are independent tests of these fits. Figure 1 also shows the fitted $\left(t_{s}-t_{o}\right)$. As a further test, the time-of-flight cut-off energy of the ions, $E_{i c}$ $\left(=(m / 2)\left\{d /\left(t_{s}-t_{o}\right)\right\}^{2}\right)$ is computed and compared with the observed value. The bottom panel of figure 1 shows the variation of the transition parameter $\tau$ during this event.

It can be seen that the model provides an explanation of the high ion pressure in the core of the event. Essentially, the field lines in the core have been opened for longer (large $t_{s}-t_{o}$ ) allowing more of the lower-energy ions to reach the satellite (lower $E_{i c}$ ), raising $N$. 

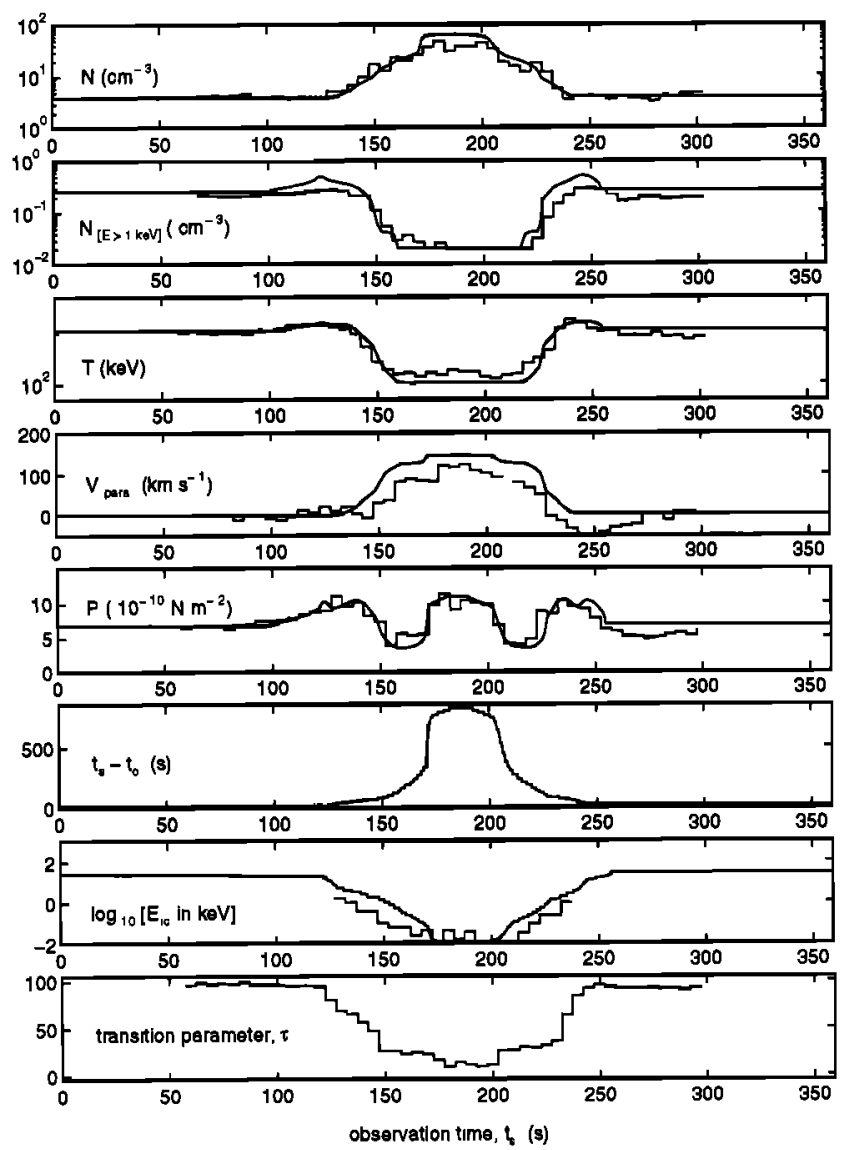

Figure 2. AMPTE UKS observations of an FTE on 28 October 1984 , plotted as a function of observation time, $t_{\mathrm{s}}$, which is zero at 10:43:00. Observed (histogram) and best-fit modelled (curves) moments of the ion gas are shown. From top to bottom: the ion density, $N$, observed in the instrument energy range of $100 \mathrm{eV}-16$ $\mathrm{keV}$, the ion density in the energy range $1-16 \mathrm{keV}, N_{[E>1 \mathrm{keV}]}$, the ion temperature, $T$, the field parallel velocity, $V_{\|} \mid$, the ion pressure, $P$, the best-fit time elapsed since reconnection $\left(t_{s}-t_{o}\right)$, the low-energy ion cut-off, $E_{i c}$ and the observed electron transition parameter $\tau$.

Figure 3 shows the variation of the transition parameter $\tau$ with the best-fit $\left(t_{s}-t_{o}\right)$ for the period shown in figure 2 . It can be seen the plot follows the same locus for the entry of the FTE as it does for the exit. In addition, figure 3 shows the predictions of a simple model (dashed line) developed by Lockwood and Hapgood [1997]. In this model, the electron density at the satellite is controlled by a potential barrier between the magnetopause and the satellite, of magnitude such that the total electron density at the satellite is the same as that of the ion gas.

The key point is that the transition parameter $\tau$ has a simple variation with time elapsed since reconnection $\left(t_{s}-t_{0}\right)$ and this explains why $\tau$ is able to order the ion and field data which also depend on $\left(t_{s}-t_{o}\right)$. For a constant distance $d$, both $\tau$ and $\left(t_{s}-t_{o}\right)$ are monotonic functions of the distance of the satellite from the magnetopause (the form of that function depending on the variation of the reconnection rate). It should be noted that in $\mathbf{4 1}$ out of $\mathbf{4 4}$ magnetopause crossings by AMPTE-UKS, the transition parameter was able to order independent magnetopause data. This implies that at least some newly-opened field lines coat most of the dayside low-latitude magnetopause most of the time, irrespective of the IMF orientation (i.e. an open LLBL is nearly always present).

\section{IMPLICATIONS FOR UNDERSTANDING FTES}

As well as producing good fits to the moments of the ion gas, as shown in figure 2 , the ion model can reproduce the energy-time spectrogram for this FTE event (the observed and modelled spectrograms have been presented by Farrugia et al. [1988] and Lockwood and Hapgood [1998], respectively). This is true for the boundary layers of this structured event, as well as the event core. Of particular importance is the fact that the event boundaries show a continuous evolution of the ion gas from the magnetospheric population to that in the event core. This is explained using the ion model by the continuous variation in $\left(t_{s}-t_{o}\right)$ with observation time $t_{s}$ shown in figure 2 . This eliminates the original "fossil flux tube" model of FTEs

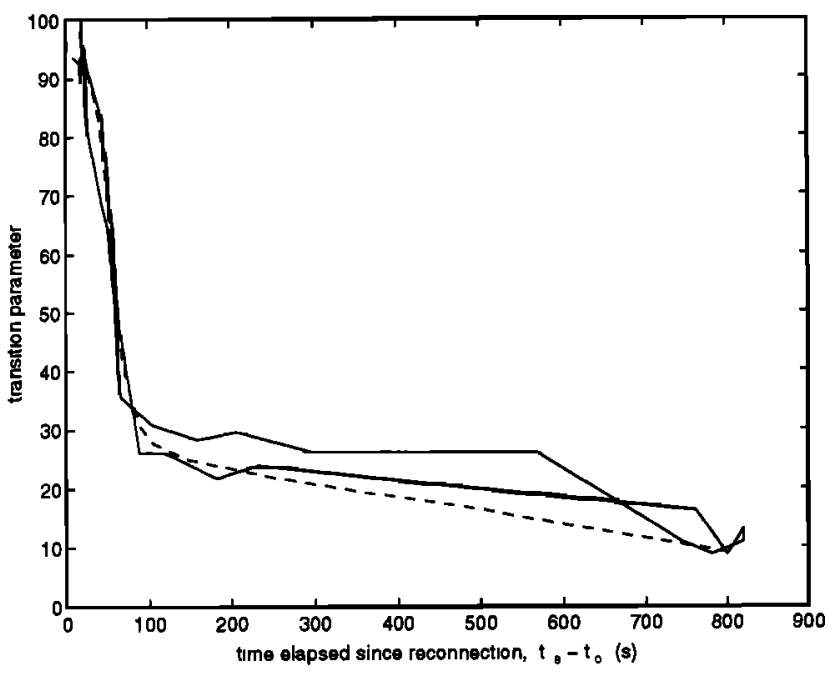

Figure 3. Solid line: hodogram showing the variation of the observed transition parameter $\tau$ with the time-elapsed since reconnection $\left(t_{\mathrm{s}}\right.$ $t_{\mathrm{o}}$ ), from the fit to the ion data shown in figure 2. Dashed line: model prediction made by applying the transition parameter to simulted electron data using the ion model and a potential barrier to maintain quasi-neutrality. 
[Russell and Elphic, 1978; 1979] as a cause of this event. This is because this model predicts a discontinuous jump in $\left(t_{s}-t_{0}\right)$ from negative to positive values (with a corresponding jump in ion characteristics) as the satellite moves from the draped closed field lines to the open field lines of the fossil flux tube when the satellite enters the event. (The converse jump would be seen on leaving the event. The only way that this model could explain this event is if there were some additional mechanism to cause the continuous evolution of ion parameters across the event boundary layer. No such mechanism has yet been proposed and is, anyway, not necessary as the boundary layer is well explained as a variation of $\left(t_{s}-t_{o}\right)$. In other words, figure 2 shows that the event is well explained as a brief entry of the satellite into the open LLBL.

The observed direction of field-aligned motion of the injected sheath ions and electrons shows that the field lines detected in the centre of this event were connected magnetically to the northern hemisphere. In other words, the outward boundary normal field component $B_{N}$ is negative where these field lines thread the boundary. The nested nature of the signals seen by UKS and IRM enable us to quantify the size of the event and to determine the speed and direction of event motion [see Lockwood and Hapgood, 1998].

Figure 4 shows the two models of FTE formation that are consistent with this finding. Figure 4(a) shows the cylindrical 2-D reconnection pulse model discussed by Southwood et al. [1988] and demonstrated by Scholer [1988; 1989] using MHD simulations and by Semenov et al., [1991; 1992a; b] using analytic theory. Figure 4(b) shows the pressure pulse model of Sibeck et al. [1990; 1992], with the important caveat that magnetopause reconnection must be ongoing throughout the event (possibility mentioned by Sibeck in his original paper). The satellite trajectory in the rest frame of the event is shown by the locus $S$. In both cases, the $\left(t_{s}-t_{0}\right)$ of the field lines sampled by the satellite increase as the satellite is immersed deeper into the open LLBL. In the reconnection pulse model (figure 4a) this occurs because of a transient thickening of the open LLBL in response to a reconnection rate pulse. In the pressure pulse model (figure $4 \mathrm{~b}$ ) it occurs because of a transient compression of the magnetopause caused by a travelling enhancement of the magnetosheath pressure. Note that both cases show an indentation of the interior RD (i), but only in 4 (b) is there a similar indentation of the exterior RD (e).

It is very difficult for a lone satellite in the magnetosphere to distinguish between these two possibilities on a case-by-case basis. However, we have been able to apply the method of Lockwood and Smith [1992], to determine the variation of the reconnection rate at which the open field lines seen in the event are produced.
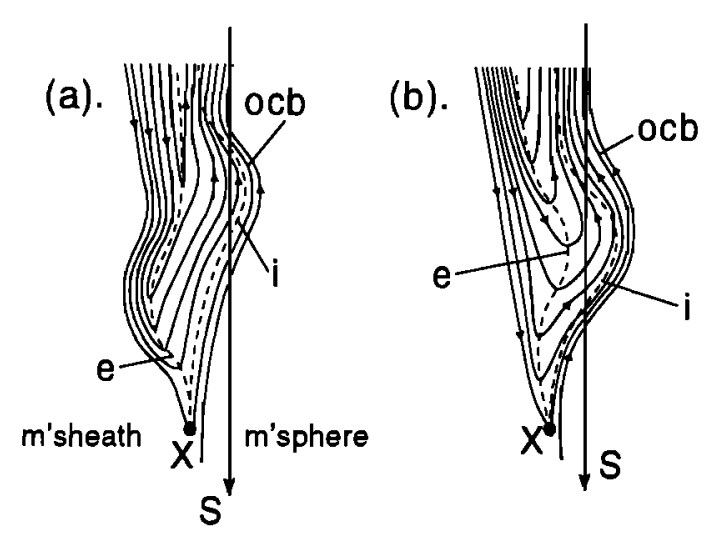

Figure 4. Explanations of the FTE event in terms of (a) the twodimensional pulse model and (b) the pressure pulse model. $\mathrm{X}$ is the reconnection site; $S$ is the satellite locus in the event rest frame; the dashed lines labelled $e$ and $i$ are the rotational discontinuities (RDs) standing on the inflow on the magnetosheath and magnetosphere sides, respectively; and ocb is the open-closed field-line boundary. (Note that the exterior RD was labelled $\mathrm{m}$ in figure 1).

This method was originally developed for ionospheric field lines in the cusp region, but has been modified by Lockwood and Hapgood [1998] to allow for the fact that the field at the magnetopause is compressible. The method has also been tested on simulated data by Lockwood and Davis [1996a]. The results are shown in figure 5, which shows the reconnection rate, computed from the variation 'of $\left(t_{s}-t_{o}\right)$ derived in figure 2 , as a function of the reconnection time, $t_{o}$. The plot shows data from both the satellite's entry into, and exit from, the event and these were found to agree when the distance $d$ was iterated to 8 $R_{E}$. Using the inferred direction of event motion, this place the reconnection site within a few $R_{B}$ of the subsolar point.

Figure 5 clearly shows that the reconnection rate was pulsed. The event core was reconnected in an earlier pulse (of which we see only the end as the satellite did not penetrate deep enough into the LLBL to see field lines opened any earlier), whereas the boundary layer (seen on both entry and exit) was reconnected in a pulse roughly 15 $\mathrm{min}$. later, these field lines being draped over the bulge in the reconnection layer caused by the first pulse. However, this detection of a reconnection pulse is necessary, but not sufficient, for proof of the reconnection pulse FTE model (in the same way that the detection of a pressure pulse in the sheath would be necessary but not sufficient for proof of the pressure pulse model). However, it is an indication in favour of the reconnection pulse model, although the high magnetosheath densities required to model the event core do suggest that a pressure pulse may also have played some role. 


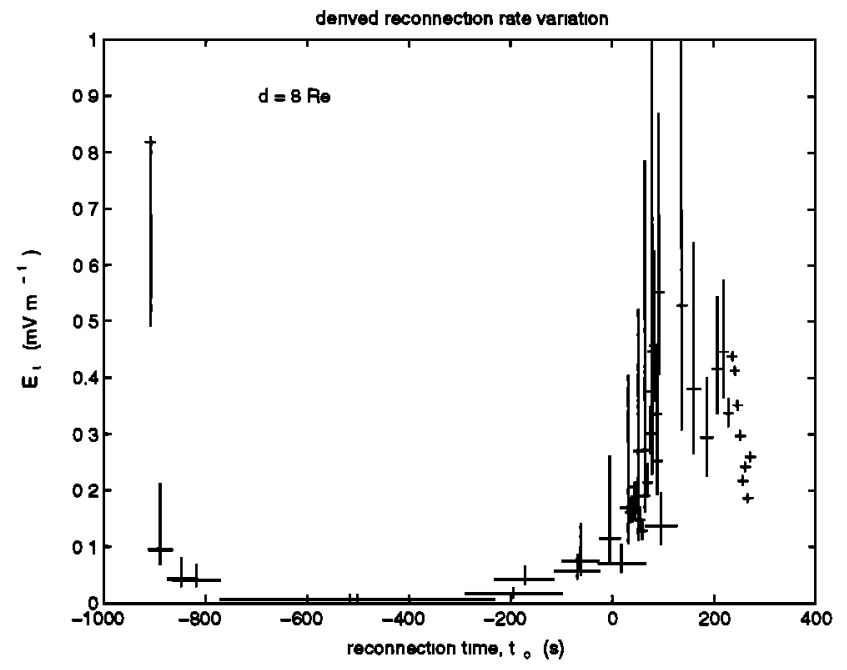

Figure 5. The reconnection rate $E_{t}$, shown as a function of reconnection time, $t_{o}$, calculated from $t_{s}$ and $\left(t_{s}-t_{o}\right)$ for a distance between the X-line and the satellite of $d=8 R_{E}$, using the theory of Lockwood and Smith [1992], with modifications to allow for a compressible field. The magnetic flux transported over AMPTE-UKS in each 5-second integration period $\left(\Delta t_{s}=5 \mathrm{~s}\right)$ is $B V_{\perp} \Delta t_{s}$, where $V_{\perp}$ is the magnitude of the field-perpendicular velocity and $B$ the magnetic field strength. The reconnection rate $E_{t}=\Delta t_{s} B V_{\perp} / \Delta t_{o}$ [Lockwood and Hapgood, 1998].

\section{IMPLICATIONS FOR UNDERSTANDING LLBL STRUCTURE}

Because it is related to $\left(t_{s}-t_{t}\right)$, the transition parameter can be used to identify structures in the LLBL, and so increase the number of observations of that structure in multiple intersections. This is particularly valuable when applying the tangential stress-balance test. Lockwood and Hapgood [1998] have generalised that test to allow for all Alfvénic disturbances, not just the RD which has been identified using the tangential stress-balance test to see if Whalén relation applies [Paschmann, 1979; 1986; Sonnerup, 1986].

Figure 1 shows a simple picture of an open LLBL with exterior and interior RDs, $m$ and $i$, propagating into the inflow on the magnetosheath and magnetospheric sides, respectively. Similarly, there may be slow mode shocks and/or slow-mode expansion fans standing in these two inflow regions and some authors have suggested there may be a contact discontinuity where the two inflows meet [see review by Lin and Lee, 1993a; b]. Because these features have different field-aligned propagation speeds they can form a layered structure in the LLBL. In general, Alfvénic disturbances propagate at a speed $V_{A} / f$, where $V_{A}$ is the local field-aligned Alfven speed and $f$ is a factor which depends on the type of disturbance [Heyn et al., 1988] (for example, $f=1$ for an $\mathrm{RD} ; f>1$ for a slow mode shock or a slow mode expansion fan; and $f=\infty$ for a contact discontinuity ). The vector subtraction of the field line velocity, $\underline{V}_{f}$, from the inflow velocity into the reconnection layer, $\underline{V}$, gives field-aligned flow speed of $V_{A} / f$. This is parallel to the field for the exterior discontinuity, but antiparallel for the interior one for this case with $B_{N}<0$. This gives:

$$
\underline{V}=\underline{V}_{f} \pm\left(\underline{V}_{A} / f\right)=\underline{V}_{f} \pm(\underline{B} / f) \cdot\left\{(1-\alpha) / \mu_{0}\right\}^{1 / 2},
$$

where $\alpha$ is the anisotropy factor $\left(\alpha=\left(P / /-P_{\perp}\right) \mu_{0} / B^{2}\right.$ where $P / /$ and $P_{\perp}$ are the total field-perpendicular and fieldparallel particle pressures) and $\rho$ is the mass density ( $\rho=$ $N m_{\mathrm{i}}$, where $m_{\mathrm{i}}$ is the mean ion mass). The + and -, in this case with $B_{N}<0$, relate, respectively, to exterior and interior disturbances, for which the field parallel flow in the field-line rest frame (the "de-Hoffman Teller frame" [de Hoffman and Teller, 1950], $V / /$, is positive and negative. Being a linear vector equation, equation (1) is valid for any component. Putting into a form equivalent to that used by Paschmann et al. [1979], but without actually applying the mass conservation condition for an RD (derived by Hudson [1970]):

$$
\underline{V}=\underline{V}_{f} \pm(\rho d \rho) \underline{B}(1 / f)\left\{(1-\alpha) \rho / \mu_{0} \rho_{o}^{2}\right\}^{1 / 2} .
$$

Note that for $f=1$, equation (2) reduces to the Whalén relation for an $\mathrm{RD}$.

Lockwood and Hapgood [1998] used the transition parameter to isolate the field rotation on the edges of the event core and obtained negative slopes in the plots of the components of $\underline{V}$ against the corresponding component of $\underline{B}$ , showing that this field rotation is an interior disturbance, and is not an exterior one because $B_{N}<0$ (i.e. it is standing in the inflow from the magnetospheric side of the boundary). Equation (2) shows that the slope of the fits for the three components should be the same for an Alfvénic disturbance. Lockwood and Hapgood [1988] found slopes of $-0.8 \pm 0.5,-0.7 \pm 0.5$ and $-0.7 \pm 0.5 \mathrm{~km} \mathrm{~s}^{-1} \mathrm{nT}^{-1}$ for the L,M and $\mathrm{N}$ components.

If we consider an RD, $f=1$ and the Hudson [1970] mass conservation condition for an RD applies, i.e. (1- $\alpha) \rho$ is constant. The theoretical slope from equation (2) is thus $\left\{\left(1-\alpha_{o}\right) / \mu_{0} \rho_{o}\right\}^{1 / 2}$ and the observed $N_{o}$ and $\alpha_{o}$ yield a slope magnitude of $3.9 \pm 0.4 \mathrm{~km} \mathrm{~s}^{-1} \mathrm{nT}^{-1}$ (the uncertainty arising from that in the mean ion mass, $m_{1}$ ). Therefore, this is not a successful application of the Whalén relation (for an $\mathrm{RD}$ ) because the observed slope of magnitude $0.75 \pm 0.50 \mathrm{~km} \mathrm{~s}$ ${ }^{1} \mathrm{nT}^{-1}$ is inconsistent with $f=1$, for any reasonable ion composition assumption. Nor is the structure a contact 
discontinuity, for which $f=\infty$ : equation (2) predicts this would give a slope of zero (for any composition of the ion gas) which is also outside the observed range of $0.75 \pm 0.50$ $\mathrm{km} \mathrm{s}^{-1} \mathrm{nT}^{-1}$.

Lockwood and Hapgood also investigated if the putative Alfvénic discontinuity could be a slow shock or a slow mode expansion fan. Heyn et al. [1988] show that $\eta<1$ for the former but $\eta>1$ for the latter, where:

$$
\eta=\left(B_{t 2} / B_{t 1}\right)=\left\{1+\beta\left(1-P_{2} / P_{1}\right)\right\}^{1 / 2},
$$

where $B_{t}$ is the discontinuity-tangential magnetic field and $P$ is the particle pressure, and where the subscripts 1 and 2 refer to upstream and downstream of the discontinuity. From the sense of the slope, and because the field-parallel flow is negative in the de-Hoffman-Teller frame, we know that the upstream side is the magnetospheric side of this structure. For this event, $P_{2}>P_{1}$ and thus by (3) $\eta<0$ and thus this structure is most likely to be a slow shock, rather than a slow-mode expansion fan. The plasma $\beta=2 P \mu_{d} / B^{2} \approx$ 0.15 and from the values of $N, T_{e}$ and $T_{i}$ upstream and downstream of the discontinuity, equation (3) yields $\eta \approx$ 0.92. However a shock is rather surprising, considering the rather extended nature of the density change (estimated above to be of order $250 \mathrm{~km}$ ) [see Lin and Lee, 1993].

The equations of Heyn et al. [1988] assume pressure isotropy $(\alpha=0)$, which is a good approximation on the edges of the event. From them, we can derive an expression for the factor $f$ appropriate to a slow shock:

$$
f=\left(\rho / \rho_{2}\right)^{1 / 2}\{1+(1+\eta) /[\gamma \beta+(\gamma-1)(1-\eta)]\}^{1 / 2},
$$

where $\gamma$ is the polytropic index. Pudovkin et al. [1997] use theory and past observations to estimate that $\gamma$ is between 1.34 and 1.95 at the bow shock, but pressure anisotropy at the magnetopause means that the effective $\gamma$ can be less than 1 . We here use the relation:

$$
\rho_{1} / \rho_{2}=\left(P_{2} / P_{1}\right)^{1 / \gamma}
$$

for the ratios of the densities and pressures across the structure to estimate $\gamma=1.2$. Using this and the mean $\beta=$ 0.15 , equation (4) yields $f=2.7$ for a slow shock. Using the mean $N$ and $\alpha$ of , respectively, $2 \times 10^{7} \mathrm{~m}^{-3}$ and -0.05 , equation (2) yields theoretical slopes of $1.1 \pm 0.1 \mathrm{~km} \mathrm{~s}^{-1} \mathrm{nT}^{-1}$. This value is still somewhat higher than the nominal observed value, but is consistent with it to within the uncertainties. Thus a slow-mode shock is a possibility.

For completeness, from the equations given by Heyn et $a l$. [1988] we can also derive an expression for $f$ for a slow-mode expansion fan:

$$
f=\left(1+V_{a t}{ }^{2} / C_{s}^{2}\right)=\left\{1+B_{t}{ }^{2} /\left(\gamma P \mu_{0}\right)\right\}^{1 / 2},
$$

where $V_{a t}$ is the boundary tangential Alfven speed (corresponding to $B_{t}$ ) and $C_{s}$ is the sound speed $=(\gamma P / \rho)^{1 / 2}$. This gives $f=3.5$ for a slow-mode expansion fan and theoretical slopes for the stress-balance test of $0.9 \pm 0.1 \mathrm{~km}$ $\mathrm{s}^{-1} \mathrm{nT}^{-1}$. This is within the range of possible experimental values of $0.75 \pm 0.50 \mathrm{~km} \mathrm{~s}^{-1} \mathrm{nT}^{-1}$ and similar to those for the slow shock.

From the above we find that the field rotation on the edges of the FTE core are a convecting structure and the consistency of the slope in the three components suggests it may be an Alfvénic discontinuity, but its speed of propagation is lower than an Alfven wave (RD) and is most likely to be a slow shock. On the magnetospheric side of this structure $V / /<0$ in the Earth's frame, as the flow is dominated by the escape of magnetospheric ions towards the magnetopause: nearer the magnetopause, within and on the other side of this structure, $V / />0$ as the flow is dominated by injected magnetosheath ions flowing Earthward.

\section{CONCLUSIONS}

The loss of Cluster was a devastating blow to ISTP studies of the LLBL. Because of it, we have turned our attention to a re-analysis of the AMPTE data, using new insights (such as of the importance of time elapsed since reconnection), techniques (such as that developed by Lockwood and Smith [1992] to compute the reconnection rate variation from cusp ion dispersion) and models (such as the injected ion model). There is a surprising wealth of new information to be gained in this way. To stress this point, we have shown how analysis of one magnetospheric FTE observed by AMPTE has:

- given an explanation of how the magnetopause transition parameter works

- explained the high particle pressure at the centre of such "core" FTEs

- explained the layer structure of the event in terms of reconnection rate variations

- identified the edge of the event core as an Alfvénic disturbance, most likely a slow shock, standing in the inflow to the reconnecting current sheet from the magnetospheric side

- shown that the field lines in the event core were reconnected in a pulse, providing support for the 2dimensional reconnection pulse theory of FTEs.

Other results have been reported by Lockwood and Hapgood [1998].

Acknowledgements. This research was carried out under a grant from the UK Particle Physics and Astronomy Research Council. The authors are also grateful to the following Principle Investigators of the AMPTE mission: David Southwood (UKS 
magnetometer), Alan Johnstone (UKS ion detector), Götz Paschmann (IRM electron and ion detectors) and Hermann Lühr (IRM magnetometer). We also thank the staff of the CDHF and WDC at RAL for maintaining and archiving the AMPTE dataset and making it readily available to us.

\section{REFERENCES}

Bryant, D.A., and S. Riggs, At the edge of the Earth's magnetosphere: a survey by AMPTE-UKS, Phil. Trans. $R$. Soc. Lond. A, 328, 43 - 56, 1989.

Cowley, S. W. H., The causes of convection in the Earth's magnetosphere: a review of developments during IMS, Rev. Geophys., 20, 531-565, 1982.

Cowley, S.W.H., and C.J. Owen, A simple illustrative model of open flux tube motion over the dayside magnetopause, Planet. Space Sci., 37, 1461, 1989.

de Hoffmann, F., and E. Teller, Magneto-hydrodynamic shocks, Phys. Rev., 80, 692, 1950.

Farrugia, C. J., R. P. Rijnbeek, M. A. Saunders, D. J. Southwood, D. J. Rodgers, M. F. Smith, C. P. Chaloner, D. S. Hall, P. J. Christiansen, and L. J. C. Woolliscroft, A multi-instrument study of flux transfer event structure, J. Geophys. Res., 93, 14465-14477, 1988.

Fuselier, S.A., D.M. Klumpar, and E.G. Shelley, Ion reflection and transmission during reconnection at the Earth's subsolar magnetopause, Geophys. Res. Lett., 18, 139-142, 1991

Hall, D.S., D.A. Bryant, and C.P. Chaloner, Plasma variations at the dayside magnetopause, Proc. 7th ESA Symposium on Rockets and Balloons, ESA SP-229, 299-304, 1985.

Hapgood, M.A., and D.A. Bryant, Exploring the magnetospheric boundary layer, Planet. Space Sci., 40, 1431-1459, 1992.

Hapgood, M.A., and M. Lockwood, Rapid changes in LLBL thickness, Geophys. Res. Lett., 22, 77-80, 1995.

Heyn, M.F., H.K. Biernat, R.P. Rijnbeek and V.S. Semenov, The structure of reconnection layers, J. Plasma Phys., 4O(2), 235-252, 1988.

Hudson, P.D., Discontinuities in an isotropic plasma and their identification in the solar wind, Planet. Space Sci., 18, 1611$1622,1970$.

Lin, Y., and L.C. Lee, The structure of reconnection layers in the magnetosphere, Space Sci. Rev., 65, 59-179, 1993.

Lockwood, M., The location and characteristics of the reconnection $\mathrm{X}$-line deduced from low-altitude satellite and ground-based observations: 1. Theory, J. Geophys. Res., 100, 21791-21802, 1995.

Lockwood, M., Energy and pitch angle dispersions of LLBL/cusp ions seen at middle altitudes: predictions by the open magnetosphere model, Ann. Geophysica, 15 , 1501-1514, 1997., 1997.

Lockwood, M., and C.J. Davis, An analysis of the accuracy of magnetopause reconnection rate variations deduced from cusp ion dispersion characteristics, Ann. Geophysicae, 14, 149-161, $1996 \mathrm{a}$.

Lockwood, M, and C.J. Davis, On the longitudinal extent of magnetopause reconnection bursts, Ann. Geophysicae, 14, 865878, 1996b.

Lockwood, M., and M.A. Hapgood, How the magnetopause transition parameter works, Geophys. Res. Lett., 24, 373-376, 1997
Lockwood, M., and M.A. Hapgood, On the cause of a magnetospheric flux transfer event, J. Geophys. Res., in press, 1998.

Lockwood, M., and J. Moen, Ion populations on open field lines within the low-latitude boundary layer: theory and observations during a dayside transient event, Geophys. Res Lett., 23, 28952898, 1996.

Lockwood, M., and M.F. Smith, The variation of reconnection rate at the dayside magnetopause and cusp ion precipitation, $J$. Geophys. Res., 97, 14,841-14,847, 1992.

Lockwood, M., and M.F. Smith, Low- and mid-altitude cusp particle signatures for general magnetopause reconnection rate variations: I - Theory, J. Geophys. Res., 99, 8531-8555, 1994.

Lockwood, M., M. F. Smith, C. J. Farrugia, and G. L. Siscoe, Ionospheric ion upwelling in the wake of flux transfer events at the dayside magnetopause, J. Geophys. Res., 93, 5641-5654, 1988.

Lockwood, M, W.F. Denig, A.D. Farmer, V.N. Davda, S.W.H. Cowley, and H. Lühr, Ionospheric signatures of pulsed magnetic reconnection at the Earth's magnetopause, Nature, 361 (6411), 424-428, 1993b.

Lockwood, M., S.W.H. Cowley, and T.G. Onsager, Ion acceleration at both the interior and exterior Alfvén waves associated with the magnetopause reconnection site: signatures in cusp precipitation, J. Geophys. Res., 101, 21501 21515, 1996.

Lockwood, M., C.J. Davis, T.G. Onsager, and J.A. Scudder, Modelling signatures of pulsed magnetopause reconnection in cusp ion dispersion signatures seen at middle altitudes, Geophys. Res. Lett., in press, 1997.

Onsager, T.G., A quantitative model of magnetosheath plasma in the low latitude boundary layer, cusp, and mantle, J.A. Holtet and A. Egeland (eds), Physical Signatures of Magnetospheric Boundary Layer Processes, pp. 385-400, 1994.

Onsager T.G., C.A. Kletzing, J.B. Austin, and H. MacKieman, Model of magnetosheath plasma in the magnetosphere: cusp and mantle particles at low-altitudes, Geophys. Res. Lett., 20, 479482, 1993

Paschmann, G., B.U.Ö. Sonnerup, I. Papamastorakis, N. Sckopke, G. Haerendel, S.J. Bame, J.R. Asbridge, J.T. Gosling, C.T. Russell, and R.C. Elphic, Plasma acceleration at the Earth's magnetopause: evidence for reconnection, Nature, 282, 243-246, 1979.

Paschmann, G., G. Haerendel, I. Papamastorakis, N. Sckopke, S. J. Bame, J. T. Gosling, and C.T. Russell, Plasma and magnetic field characteristics of magnetic flux transfer events, J. Geophys. Res., 87, 2159-2168, 1982.

Paschmann, G., I. Papamastorakis, W. Baumjohann, N. Sckopke, C.W. Carlson, B.U.Ö. Sonnerup, and H. Lühr, The magnetopause for large magnetic shear: AMPTE/RM observations, J. Geophys. Res., 91, 11099-11115, 1986.

Phan, T.D., et al., Low-latitude flank magnetosheath, magnetopause and boundary layer for low magnetic shear: Wind observations, J. Geophys. Res., 102, 19,883-19,895, 1997.

Pinnock, M., A.S. Rodger, J.R. Dudeney, F. Rich, and K.B. Baker, High spatial and temporal resolution observations of the ionospheric cusp, Ann. Geophys., 13, 919-925, 1995.

Reiff, P. H., T. W. Hill, and J. L. Burch, Solar wind plasma injection at the dayside magnetospheric cusp, $J$. Geophys. Res., 82, 479 491,1977 
Rijnbeek R. P., C. J. Famugia, D. J. Southwood, M. W. Dunlop, W. A. C. Mier-Jedrejowicz, C. P. Chaloner, D. S. Hall, and M. F. Smith, A magnetic boundary signature within flux transfer events, Planet. Space Sci., 35, 871-878, 1987.

Rosenbauer, H., H. Grünwaldt, M.D. Montgomery, G. Paschmann, and N. Skopke, HEOS-2 plasma observations in the distant polar magnetosphere: the plasma mantle, J. Geophys. Res.,80, 2723$2737,1975$.

Russell, C. T., and R. C. Elphic, Initial ISEE magnetometer results: magnetopause observations, Space Sci. Rev., 22, 681-715, 1978.

Russell, C. T., and R. C. Elphic, ISEE observations of flux transfer events at the dayside magnetopause, Geophys. Res. Lett., 6, 33-36, 1979.

Sandholt, P.E., M. Lockwood, T. Oguti, S.W.H. Cowley, K.S.C. Freeman, A. Egeland, B. Lybekk and D.M. Willis, Midday auroral breakup events and related energy and momentum transfer from the magnetosheath, J. geophys. Res., 95, 1039-1061, 1990.

Scholer, M., Magnetic flux transfer at the magnetopause based on single X-line bursty reconnection, Geophys. Res. Lett., 15, 291-294, 1988a.

Scholer, M., Asymmetric time-dependent and stationary magnetic reconnection at the dayside magnetopause, J. Geophys. Res., 94, 15099-15111, 1989.

Sckopke, N., G. Paschmann, G. Haerendel, B.U.Ö. Sonnerup, S.J. Bame, T.G. Forbes, E.W. Hones, Jr., and C.T. Russell , Structure of the low latitude boundary layer, J. Geophys. Res. 86, 20992110. 1981

Semenov, V.S., I.V. Kubyshkin, H.K. Biemat, M.F. Heyn, R.P. Rijnbeek, B.P. Besser, and C.J. Farrugia, Flux transfer events interpreted in terms of a generalized model for Petschek-type reconnection, Adv. Space, Res., 11, (9)25-(9)28, 1991.

Semenov, V.S., IV. Kubyshkin, V.V. Lebedeva, R.P. Rijnbeek, M.F.
Heyn, H.K. Biernat, and C.J. Farrugia, A comparison and review of ready-state and time-varying reconnection, Planet. Space Sci., 40, 63-87, 1992a.

Semenov, V.S., I.V. Kubyshkin, V.V. Lebedeva, M.V. Sidneva, H.K. Biemat, M.F. Heyn, B.P. Besser, and R.P. Rijnbeek, Timedependent localized reconnection of skewed magnetic fields, $J$. Geophys. Res., 97, 4251-4263, $1992 \mathrm{~b}$.

Sibeck, D. G., A model for the transient magnetospheric response to sudden solar wind dynamic pressure variations, J. Geophys. Res., 95, 3755-3771, 1990.

Sibeck, D.G., Transient events ion the outer magnetosphere, boundary waves or flux transfer events, J. Geophys. Res., 97, 4009-4026, 1992.

Sibeck D.G., and M.F. Smith, Magnetospheric plasma flows associated with boundary waves and flux transfer events, Geophys. Res. Lett., 19, 1903-1906, 1992.

Smith, M.F., and C.J. Owen, Temperature anisotropies in a magnetospheric FTE, Geophys. Res. Lett., 19, 1907-1910, 1992.

Sonnerup, B.U.Ö., I Papamastorakis, G. Paschmann, and H. Lühr, The magnetopause for large magnetic shear: analysis of convection electric fields from AMPTE/RM, J. Geophys. Res., 95, 10541-10557, 1986.

Spreiter, J.R., A.L. Summers, and A.Y. Alksne, Hydromagnetic flow around the magnetosphere, Planet. Space Sci., 14, 223-253, 1966.

Southwood, D. J., C. J. Farrugia, and M. A. Saunders, What are flux transfer events?, Planet. Space Sci., 36, 503-508, 1988

M.A.Hapgood and M. Lockwood, Rutherford Appleton Laboratory, Chilton, Didcot, Oxon., OX11 0QX, England, UK. (email: m.lockwood@rl.ac.uk) 